\title{
Merkel Cell Carcinoma of the Mandible: A Case of Spontaneous Acceleration of the Growth
}

\author{
Mansoor Choudhry ${ }^{1}$, Muhammad Danial ${ }^{1}$, James Bolduc ${ }^{1}$, Syed A. A. Rizvi ${ }^{2, *}$, \\ Pedro Rabionet ${ }^{3}$ and John Westine ${ }^{3}$ \\ 1 Patel College of Osteopathic Medicine, Nova Southeastern University, Fort Lauderdale, FL 33314, USA \\ 2 School of Pharmacy, Hampton University, Hampton, VA 23668, USA \\ 3 Bethesda Hospital East, Miami, FL 33435, USA \\ * Correspondence: syed.rizvi@hamptonu.edu; Tel.: +01-757-727-5455
}

Received: 21 July 2019; Accepted: 26 August 2019; Published: 2 September 2019

\begin{abstract}
A 78 year old Caucasian woman, was admitted to the hospital for evaluation of a mass to the anterior surface of the left mandibular angle and left submandibular area present for the past year with rapid acceleration of growth over three weeks prior to admission. An incisional biopsy was performed and initial diagnosis of poorly differentiated neuroendocrine carcinoma (small cell carcinoma) was made. Dermatological evaluation revealed lesion was suspicious for Merkel cell carcinoma and the pathology specimen was re-analyzed and differential diagnoses was made for Merkel cell carcinoma. Patient was educated and discharged to a nursing home with plan for irradiation, chemotherapy, and outpatient follow up. This case study serves to raise awareness of a rare condition and describe how Merkel cell carcinoma may be mistaken for similarly presenting neuroendocrine tumors.
\end{abstract}

Keywords: merkel cell carcinoma; mandible; spontaneous accelerated growth; neuroendocrine carcinoma; tumor

\section{Introduction}

Merkel cell carcinoma (MCC) is a rare and highly aggressive neuroendocrine carcinoma with etiology related to the Merkel-Ranvier tactile epithelial cells necessary for light touch. Majority of all the reported cases of Merkel cell carcinomas are caused by Merkel Cell Polyomavirus (MCPyV), which incorporates itself into the genome of cancerous Merkel cells leading to a monoclonal proliferation-a pattern indicating the virus initially integrated into a single cell [1]. Furthermore, Shuda et al., in 2008 demonstrated MCPyV infected Merkel cells may contain specific T-antigen specific mutations rendering them susceptible to $\mathrm{MCPyV}$ infection and progression to carcinoma [2].

Direct evidence for an oncogenetic basis of tumorigenesis was further provided by Houben et al. who found via inactivation of protein expression in MCPyV infected Merkel cells that protein expression was necessary in order to "maintain the tumor phenotype-the so-called oncogene addiction" [3]. The cases not attributable to MCPyV have an unknown etiology [4], but evidence exists for UV associated mutations "underlying the etiology of MCPyV-negative Merkel cell carcinomas" [5]. Although MCC is not a common cancer, incidence in the US has "tripled between 1986 and 2001" to approximately 1400 cases per year [6]. Merkel Cell carcinomas commonly occur on sun exposed areas such as the head, neck, extremities, and major risk factors include UV light exposure, advanced age, and immunosuppressed states [7]. "Immunodeficiency conditions are related both to polyomavirus-associated and to UV-associated MCC, suggesting that immune system's alteration plays a role in the pathogenesis of both types of MCC" [8]. 


\section{Case Presentation Section}

We present a case of a 78 year old Caucasian woman (oral informed consent was obtained), with past medical history significant for cerebral palsy, congestive heart failure, hypertension, and type two diabetes mellitus who was admitted for evaluation of a mass to the anterior surface of the left mandibular angle and left submandibular area present for the past year with rapid acceleration of growth over three weeks prior to admission. The three week period resulted in the tripling of size, onset of violaceous coloring, and onset of severe pain. On examination, there was an immobile, erythematous, edematous, and violaceous mass with telangiectasias to the anterior left mandibular angle without fluctuance, bleeding, or discharge. No lymphadenopathy was appreciated on exam. In order to evaluate for metastasis, imaging was performed. CT of the neck found a $4.7 \mathrm{~cm} \times 3.7 \mathrm{~cm}$ $\times 4.6 \mathrm{~cm}$ mass without any glandular or bony involvement (Figure 1). MRI of the neck revealed left supraclavicular adenopathy as well as no intracranial metastatic disease and no small vessel disease. $\mathrm{CT}$ of the chest, abdomen, and pelvis revealed no metastatic disease.

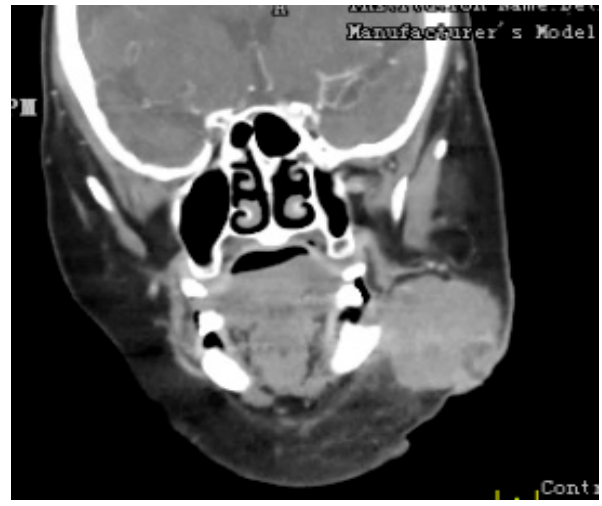

(a)

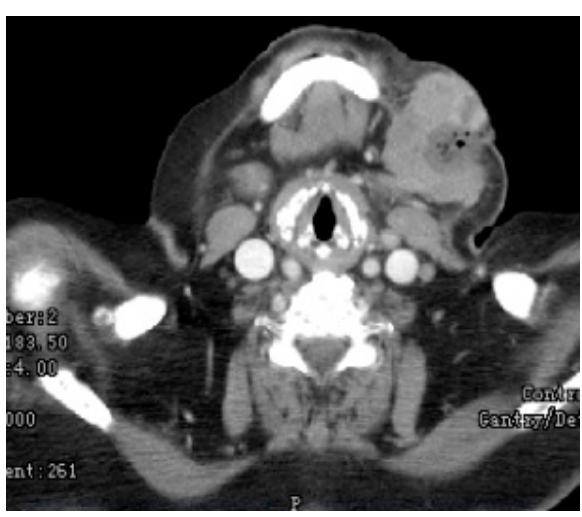

(b)

Figure 1. (a) Coronal; (b) Axial CT images showing, the mandibular mass.

An incisional biopsy was performed without complication: a $3 \mathrm{~cm} \times 2 \mathrm{~cm}$ piece of the inferior border of the tumor was excised as a specimen. Initial pathological interpretation of the specimen resulted in a diagnosis of poorly differentiated neuroendocrine carcinoma (small cell carcinoma). CD56, chromogranin, synaptophysin, and pankeratin immunostains were positive in tumor cells (Figure 2). The CD3 immunostain highlighted reactive small T-cell lymphocytes and CD20 immunostain revealed few reactive B-cell lymphocytes.

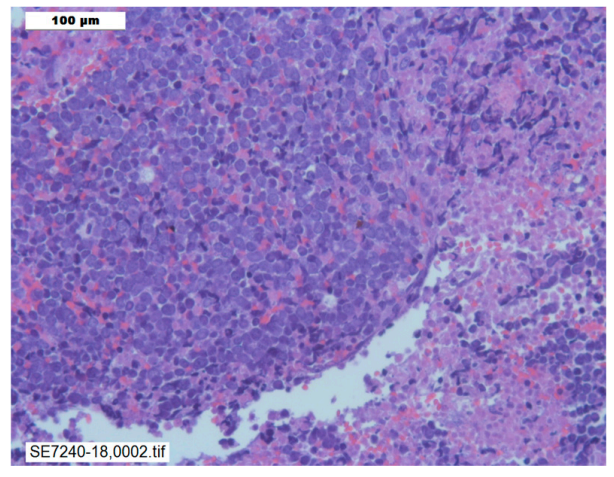

(a)

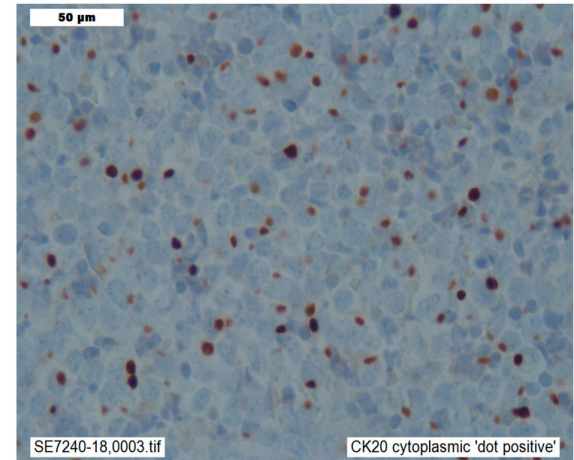

(b)

Figure 2. (a) Histology: Hematoxylin and eosin staining showing small round cells, hyperchromic nuclei of various size, numerous apoptotic figures, powdery chromatin, consistent with nonspecific findings of neuroendocrine carcinomas; (b) Immunostaining: Cytokeratin 20 (CK20) staining showing membranous and paranuclear dotlike pattern, a specific characteristic of Merkel cell carcinoma. 
Dermatological evaluation revealed lesion was suspicious for Merkel cell carcinoma and the pathology specimen was re-analyzed. Histologic sections showed a proliferation of small round blue cells with a high nuclear:cytoplasmic $(\mathrm{N}: \mathrm{C})$ ratio and extraordinarily scant cytoplasm. The nuclei were round with stippled chromatin and focal nuclear molding. Additional CK7, TTF1, and CK20 immunostains were performed. TTF1 and CK7 immunostains were negative. CK20 immunostaining was positive for a perinuclear dot-like pattern (Figure 2B) resulting in an amendment of the diagnosis to Merkel cell carcinoma.

Oncological consult resulted in plan for Carboplatin/Etoposide therapy and a peripherally inserted central catheter (PICC) was placed for administration of chemotherapy. A 3-day course of Carboplatin/ Etoposide therapy was initiated with plan for subsequent therapy every three weeks for a total of six cycles. Patient was prophylactically started on a 5-day course of Filgrastim for prevention of neutropenia. Radiation oncology consultation was obtained, resulting in plan for outpatient irradiation of the mass. The patient followed up after three cycles of chemotherapy, there was notable reduction in the left facial mass and central ulceration.

\section{Discussion}

Once thought to be a benign tumor, Merkel cell carcinoma is a rare malignant neuroendocrine tumor of the skin commonly presenting in elderly males of European descent in areas of UV light exposure. MCC commonly presents as a rapidly growing, violaceous, dome-shaped mass. In 2008, a cohort study following 195 patients found $88 \%$ of MCCs were nontender [9]. Merkel cell carcinoma of the mandibular or submandibular glad is extremely rare and there are only a handful of case reports on this topic, although MCC is well known to affect the skin of the head and neck [10,11].

Our patient was an elderly female who unusually presented with an initially stagnant phase of growth followed by a rapid enlargement. In addition, the mass was painless at the beginning for approximately an entire year after which, it rapidly became painful commensurate with growth. Certain primary cancers like malignant melanoma, non-Hodgkin's lymphoma, multiple myeloma, and Chronic lymphocytic leukemia are associated with an increased risk of subsequently developing MCC; none of which were present in our patient [12]. The patient was not immunosuppressed, another attribute which can increase the risk of MCC up to 24-fold, compared to the general population [13]. The increased incidence in immunosuppressed patients provides further evidence for a viral etiology of MCC.

Due to its atypical clinical picture and positive neurofilament and neuroendocrine markers like synaptophysin and chromogranin, the diagnosis of small cell carcinoma (SCC) was made as it could not be ruled out and is a more common condition than MCC. Due to the suspicious presentation, further testing was done to reveal positive cytokeratin immunohistochemistry (CK20), which is characteristic of MCC and excludes SCC [14]. Histologically, MCC appears as small, round, blue cells with sparse cytoplasm, medium to large-sized hyperchromatic nuclei, multiple small nucleoli, delicately granular chromatin, abundant mitoses and numerous apoptotic figures. "MCC is occasionally mistaken for other histologically related cutaneous tumors such as small cell lung carcinoma or extra skeletal primitive neuroendocrine tumors" [15].

\section{Conclusions}

This case study presents an unusual progression of a soft tissue mandibular Merkel cell carcinoma mistaken for poorly differentiated neuroendocrine carcinoma (small cell carcinoma). Furthermore, it highlights the importance of comprehensive diagnostic and teamwork in proper identification of this rare but lethal cancer with mortality rate up to $33 \%$ to $46 \%$. In case of localized MCC, the five-year survival rate is $55.6 \%$ and for advanced stage, it is about $35.4 \%$. In patients with advanced disease, historical five-year survival is $35.4 \%$ for those with regional nodal disease and $13.5 \%$ for those with distant metastases [16]. The case is important in its unique presentation and serves to highlight how Merkel cell carcinomas can commonly be mistaken for neuroendocrine carcinomas like small cell 
carcinoma. As further research is done and more is learned about Merkel cell carcinoma, treatment modalities may change and allow for more targeted therapy after correct diagnosis.

Author Contributions: Conception and design, M.C.; M.D.; J.B.; P.R.; and J.W.; writing-original draft preparation, M.D. and S.A.A.R.; writing一review and editing, M.D. and S.A.A.R.

Conflicts of Interest: The authors declare no conflict of interest.

\section{References}

1. Feng, H.; Shuda, M.; Chang, Y.; Moore, P.S. Clonal integration of a polyomavirus in human Merkel cell carcinoma. Science 2008, 319, 1096-1100. [CrossRef] [PubMed]

2. Shuda, M.; Feng, H.; Kwun, H.J.; Rosen, S.T.; Gjoerup, O.; Moore, P.S.; Chang, Y. T antigen mutations are a human tumor-specific signature for Merkel cell polyomavirus. Proc. Natl. Acad. Sci. USA 2008, 105, 16272-16277. [CrossRef] [PubMed]

3. Houben, R.; Shuda, M.; Weinkam, R.; Schrama, D.; Feng, H.; Chang, Y.; Moore, P.S.; Becker, J.C. Merkel cell polyomavirus-infected Merkel cell carcinoma cells require expression of viral T antigens. J. Virol. 2010, 84, 7064-7072. [CrossRef] [PubMed]

4. Schrama, D.; Ugurel, S.; Becker, J.C. Merkel cell carcinoma: Recent insights and new treatment options. Curr. Opin. Oncol. 2012, 24, 141-149. [CrossRef] [PubMed]

5. Wong, S.Q.; Waldeck, K.; Vergara, I.A.; Schröder, J.; Madore, J.; Wilmott, J.S.; Colebatch, A.J.; De Paoli-Iseppi, R.; $\mathrm{Li}$, J; Lupat, R.; et al. UV-associated mutations underlie the etiology of MCV-negative Merkel cell carcinomas. Cancer Res. 2015, 75, 5228-5234. [CrossRef] [PubMed]

6. Bichakjian, C.K.; Lowe, L.; Lao, C.D.; Sandler, H.M.; Bradford, C.R.; Johnson, T.M.; Wong, S.L. Merkel cell carcinoma: Critical review with guidelines for multidisciplinary management. Cancer 2007, 110, 1-12. [CrossRef] [PubMed]

7. Schadendorf, D.; Lebbé, C.; Zur Hausen, A.; Avril, M.F.; Hariharan, S.; Bharmal, M.; Becker, J.C. Merkel cell carcinoma: Epidemiology, prognosis, therapy and unmet medical needs. Eur. J. Cancer 2017, 71, 53-69. [CrossRef] [PubMed]

8. Barksdale, S.K. Advances in Merkel cell carcinoma from a pathologist's perspective. Pathology 2017, 49, 568-574. [CrossRef] [PubMed]

9. Heath, M.; Jaimes, N.; Lemos, B.; Mostaghimi, A.; Wang, L.C.; Peñas, P.F; Nghiem, P. Clinical characteristics of Merkel cell carcinoma at diagnosis in 195 patients: The AEIOU features. J. Am. Acad. Dermatol. 2008, 58, 375-381. [CrossRef] [PubMed]

10. Islam, M.N.; Chehal, H.; Smith, M.H.; Islam, S.; Bhattacharyya, I. Merkel cell carcinoma of the buccal mucosa and lower lip. Head Neck Pathol. 2018, 12, 279-285. [CrossRef] [PubMed]

11. Lombardi, D.; Accorona, R.; Ungari, M.; Melocchi, L.; Bell, D.; Nicolai, P. Primary Merkel cell carcinoma of the submandibular gland: When CK20 status complicates the diagnosis. Head Neck Pathol. 2015, 9, 309-314. [CrossRef] [PubMed]

12. Howard, R.A.; Dores, G.M.; Curtis, R.E.; Anderson, W.F.; Travis, L.B. Merkel cell carcinoma and multiple primary cancers. Cancer Epidemiol. Prev. Biomark. 2006, 15, 1545-1549. [CrossRef] [PubMed]

13. Clarke, C.A.; Robbins, H.A.; Tatalovich, Z.; Lynch, C.F.; Pawlish, K.S.; Finch, J.L.; Hernandez, B.Y.; Fraumeni,J.F.,Jr;; Madeleine, M.M.; Engels, E.A. Risk of Merkel cell carcinoma after solid organ transplantation. J. Natl. Cancer Inst. 2015, 107, dju382. [CrossRef] [PubMed]

14. Shah, I.A.; Netto, D.; Schlageter, M.O.; Muth, C.; Fox, I.; Manne, R.K. Neurofilament immunoreactivity in Merkel-cell tumors: A differentiating feature from small-cell carcinoma. Mod. Pathol. 1993, 6, 3-9. [PubMed]

15. He, W.; Zhang, D.; Jiang, J.; Chen, Y.; Wu, C. Merkel cell carcinoma in the left groin: A case report and review of the literature. Oncol. Lett. 2015, 9, 1197-1200. [CrossRef] [PubMed]

16. Chan, I.S.; Bhatia, S.; Kaufman, H.L.; Lipson, E.J. Immunotherapy for Merkel cell carcinoma: A turning point in patient care. J. Immunother. Cancer 2018, 6, 23. [CrossRef] [PubMed] 